\title{
CONCILIANDO A LIDERANÇA E A MATERNIDADE: UM ESTUDO COM RECURSO A HISTÓRIAS DE VIDA
}

\section{BALANCING LEADERSHIP AND MOTHERHOOD: A STUDY USING LIFE STORIES}

\section{Catarina do Vale Brandão', Diana Gabriela Lopes²}

'Autora para correspondência. Doutora em Psicologia. Docente na Universidade do Porto. Porto, Portugal. http://orcid.org/0000-0002-4305-5605. catarina@fpce.up.pt ${ }^{2}$ Mestre em Psicologia pela Universidade do Porto. Porto, Portugal. http://orcid.org/0000-0001-9231-0644.up201506974@fpce.up.pt

RESUMO | Este estudo explora a vivência da liderança feminina e a conciliação deste papel com a maternidade. A recolha de dados aconteceu junto de quatro mulheres líderes e com filhos. Recorreuse ao método de histórias de vida, realizando-se duas entrevistas com cada participante. Os dados foram sujeitos à análise de conteúdo temática, com recurso ao NVivol 1. Os resultados apontam que a liderança é assumida pelas participantes como um papel que acarreta dificuldades, sendo a conciliação entre a esfera pessoal e profissional uma dessas dificuldades, assim como o exercício da autoridade associado ao seu papel de líder. Referem ainda a existência de descriminação, ainda que não assumam que a experienciam na sua organização de trabalho. As expetativas destas líderes passam pela melhoria de condições de trabalho, desenvolvimento de competências, vontade de permanecer no cargo ou organização atual e empreender. As mulheres têm uma evidente sobrecarga a nível das tarefas domésticas e no cuidar dos filhos, sendo difícil conciliar estes papéis.

Palavras-chave: liderança feminina, maternidade, histórias de vida.

\begin{abstract}
This study explores the experience of female leadership and the balancing of this role with motherhood. Data collection took place among four women leaders with children. We used the method of life histories, conducting two interviews with each participant. The data was subject to thematic content analysis, using NVivo. Results show that participants assume leadership as a position that entails difficulties, with the conciliation between the personal and professional sphere being one of these difficulties, as well as the exercise of the authority associated with their role as leader. They also refer to the existence of discrimination, even if they do not assume they experienced it in the organization where they currently work. These leaders' expectations are to improve their working conditions, skills development, and the willingness to remain in their current position or organization. Women have a clear overload on household chores and childcare, and it is difficult to reconcile these roles.
\end{abstract}

Key words: female leadership, motherhood, life stories. 


\section{INTRODUÇÃO}

As mulheres desempenham vários papéis e funções nas organizações, mas apenas algumas conseguem alcançar funções de liderança (Kanan, 2010), sendo ainda quase invisíveis nessas posições (Nogueira, 2006). Os estereótipos de género realçam a perceção de que a qualidade da liderança feminina é inferior à da masculina, ao mesmo tempo que subestimam as ações desenvolvidas por líderes femininas (Manning, 2002). Paralelamente, parecem existir poucos elementos no processo de educação da mulher que a preparam para liderar (Kanan, 2010).

Apesar de alguns autores (e.g., Kanan, 2010) referirem que existem caraterísticas femininas que são entendidas como não adequadas para liderar, Nogueira (2006) defende que caraterísticas consideradas femininas, como a paciência, a comunicação e a sensibilidade social, são cada vez mais entendidas como promotoras de sucesso organizacional. Assim como a experiência das tarefas domésticas, que permitem adquirir competências de gestão e organização, que podem ser uma maisvalia para as organizações, tornando-as mais flexíveis para se adaptarem a diferentes situações. Também Teixeira (2001) avança que as mulheres possuem caraterísticas para serem boas líderes, nomeadamente, a generosidade, a harmonia, a capacidade de comunicação, a habilidade de liderar de maneira mais participativa e cooperativa, a capacidade para negociar e resolver problemas, com empatia e racionalidade. Já os homens deixarse-ão guiar mais pela competitividade e autoridade, resolvendo os problemas de forma analítica e sem emoções.

Alguns autores (e.g., Moller \& Gomes, 2010) indicam que as mulheres adotam um estilo de liderança mais democrático e centrado nas relações, enquanto os homens preferem um estilo mais diretivo e centrado nas tarefas. Defendem ainda que homens e mulheres têm valores e princípios diferentes, referindo que a liderança feminina é aquela que mais valoriza os indivíduos como seres humanos e que tem em conta os seus valores e necessidades individuais, promovendo horários mais flexíveis e incentivando a educação. Cotter, DeFiore, Hermsen, Kowalewski e Vanneman (1997) defendem que quantas mais mulheres ocuparem funções de liderança, com responsabilidades a nível de salários, promoções, contratações e demissões, menores serão as diferenças entre géneros.

Apesar de minoritários, alguns estudos contrariam estes resultados. Não associam a eficácia da liderança ao género, defendendo que homens e mulheres são líderes igualmente eficazes (Duarte, D'Oliveira, \& Gomes, 2009) e que os estilos de liderança transformacional e transacional podem ser adotados por homens e mulheres (Duarte et al., 2009; Santos \& Antunes, 2012). Pinheiro, Batista e Freitas (2014) entendem que não existe um modelo feminino de liderança que se oponha ao masculino, considerando que a liderança é independente do género, estando mais relacionada com as competências dos indivíduos. Estes estudos sublinham a importância de se considerarem variáveis para além do género, nomeadamente a flexibilidade comportamental, o contexto, o tipo de organização, a situação socioeconómica, variáveis de índole grupal (Duarte et al., 2009), assim como a modificação da cultura e da organização da sociedade ao longo do tempo (Kanan, 2010).

Segundo Nogueira (2006) as mulheres são sujeitas a dois tipos de discriminação nas organizações e que se traduzem nas suas principais barreiras: a discriminação formal e a discriminação informal. A discriminação formal corresponde às políticas da organização, podendo observar-se, por exemplo, nas questões salariais. $O$ trabalho da mulher, mesmo sendo semelhante ao executado por um homem tem, em muitas organizações, menos valor (Kanan, 2010). Especificamente em Portugal, a análise dos salários entre os dois géneros em 2007 permite perceber que a discriminação entre homens e mulheres era relevante (Dias, 2007). No ano de 2015 a mulher da União Europeia apresentava uma diferença salarial em comparação com o homem de 16,3\% (EUROSTAT, 2017).

A discriminação informal é a exercida por sujeitos, que podem ser pares e/ou superiores. Um exemplo será $\circ$ assédio sexual ou moral, muitas vezes praticado sobre o género feminino no ambiente de trabalho (Dias, 2008; Silva, 2014). As organizações que aceitam e promovem culturas com práticas de género discriminatórias, normalmente favorecem um mau ambiente entre trabalhadores, o que pode levar 
a práticas de assédio e hostilidade contra o género feminino (Dias, 2008). Quando os trabalhadores são na sua maioria do género masculino ou este predomina na estrutura hierárquica, também aumenta o risco de assédio sexual. Este tipo de comportamento favorece uma evolução lenta nas carreiras profissionais das mulheres, para além de contribuir para as diferenças salariais entre homens e mulheres (Dias, 2008). É comum a mulher experienciar assédio moral ou preconceito no seu ambiente de trabalho, situações normalizadas pelo padrão cultural da sociedade (Silva, 2014) e mulheres em posições de poder têm dificuldades no começo das suas carreiras, experienciando discriminação por parte dos colegas masculinos (Nogueira, 2006). Segundo Nogueira (2006) as mulheres têm que provar que são melhores do que os homens para serem aceites para os mesmos lugares.

\section{Ambições profissionais das mulheres}

As ambições do género feminino são mais elevadas e completas do que as do género masculino no que diz respeito à área profissional (Diniz, 2004). A mulher atualmente assume um papel diferente, procurando estudar e, qualificar-se, sustenta-se a si própria e a uma casa, procura ser independente (Fontenele-Mourão, 2006), sendo competitiva e esforçando-se por alcançar os seus objetivos. $O$ facto de por vezes as mulheres serem discriminadas, nomeadamente a nível de salários, pode levar a que percam autoridade e a sua posição em várias organizações, conduzindo-as a expetativas mais baixas e a sentimentos de menos-valia (Downes, Hemmasi, \& Eshghi, 2014).

Durante o século XXI ○ género feminino deverá ultrapassar o masculino no que diz respeito ao número de postos de trabalho que ocupa (FonteneleMourão, 2006). A mulher terá, assim, a oportunidade de ter maior impacto no mercado de trabalho, terminando-se com as hierarquias empresariais moldadas pelo homem (Probst \& Ramos, 2003). Um exemplo concreto das ambições das líderes femininas relaciona-se com o empreendedorismo. Muitas líderes ao verem-se confrontadas com as desigualdades de género e com a dificuldade em ascender ou manter a sua posição nas organizações, optam por abandonar os seus empregos e empreender por conta própria. Desta forma podem alcançar o êxito pelos seus próprios meios, obter - crescimento pessoal, profissional e financeiro tão desejado e que até então era impedido por terceiros (Munhoz, 2000; Amorim \& Batista, 2012).

\section{A Maternidade e a Carreira de Líder}

A conciliação trabalho família é um dos desafios que se coloca às mulheres (Knudsen, 2009), sendo difícil de conseuir devido às alterações familiares que têm vindo a ocorrer e às actuais elevadas exigências a nível profissional (Gonçalves, 2011). Em Portugal a tarefa de cuidar dos filhos é tradicionalmente atribuída às mulheres (Guerreiro, Lourenço, \& Pereira, 2006) e, por isso, a pressão exercida sobre estas é muito mais forte (Neto et al., 2010). Um estudo da Comissão para a lgualdade no Trabalho e no Emprego em Portugal, que foi notícia em junho de 2016 no jornal Observador, confirma esta ideia, referindo que é à mãe que cabe a obrigação de garantir o bem-estar da criança nos primeiros meses de vida, enquanto o pai garante a suficiência económica, auxiliando a nível dos cuidados físicos ou emocionais (Perista, 2016).

Torna-se assim fundamental perceber de que forma a mulher que ocupa uma posição de liderança concilia os papéis de mãe e profissional (Lopes \& Brandão, 2017). Silva (2014) considera que o mercado de trabalho ainda não aprendeu a gerir esta relação e parece que, no que respeita à mulher de hoje, uma das discussões mais difíceis, complexas e capazes de gerar conflitos continua a ser a maternidade (RochaCoutinho, 2005). Apesar das mudanças que têm vindo a ocorrer, permanece a crença de que a vivência a tempo inteiro entre mãe e filho é essencial e a mais apropriada quer para $\circ$ desenvolvimento saudável da criança, como para a mãe se sentir completa e realizada (Rocha-Coutinho, 2005). Estas crenças entram em conflito com outros aspetos importantes para as mulheres, como a necessidade de investir numa carreira profissional e a luta pela igualdade de funções. Isto obriga-as a tentarem conciliar a família e a carreira, o que nem sempre é conseguido (Rocha-Coutinho, 2005). Além disso, os primeiros anos de ascensão na carreira profissional correspondem à idade fértil ou mais apropriada biologicamente para a mulher ter filhos, que ronda os 35 anos (Virtala, Kunttu, Huttunen, \& Virio, 2006), o que se traduz numa dificuldade acrescida para a mulher que pretende 
ser mãe e ocupa ou pretende vir a ocupar um posto de liderança (Neto et al., 2010).

Rocha-Coutinho (2005) realizou um estudo com 15 mulheres bem-sucedidas profissionalmente, observando que $\circ$ ter de se preocupar com as tarefas domésticas, a educação dos filhos e, ainda, com a atualização profissional e o bom desempenho no trabalho é prejudicial para o plano de carreira e pessoal de qualquer indivíduo. Em consequência, pode surgir o desinvestimento na carreira ou mesmo - abandono (definitivo ou temporário) da carreira profissional, a favor de um maior investimento na maternidade. Por outro lado, em alguns casos pode acontecer um adiamento da maternidade para uma preservação da carreira (Beltrame \& Donelli, 2012). Para Rocha-Coutinho (2005) a mulher que tiver maiores ambições e quiser subir ao topo da hierarquia, dificilmente conseguirá ser mãe, na medida em que quanto mais alta a função ou o cargo exercido pela mulher, menor será a disponibilidade da mesma para se dedicar à vida pessoal e familiar.

A mulher tem procurado estratégias para gerir a maternidade com a presença no mundo do trabalho (Rocha-Coutinho, 2005). As redes de apoio (e.g., escolas, creches, vizinhos, avós) são uma das formas possíveis de conciliar a vida familiar com a vida profissional após o bebé nascer (Almeida, 2007; Souza, Teixeira, Loreto, \& Bartolomeu, 2011 1). A opção de cuidados dependerá do contexto e das crenças da família (Beltrame \& Donelli, 2012). É também importante que o cuidado dos filhos seja entendido enquanto uma responsabilidade partilhada pelo casal', sob pena das obrigações e os benefícios da maternidade forçarem a mulher para segundo plano nas outras esferas da vida, nomeadamente no emprego. Um desafio fundamental que se coloca à mulher é, então, o de viver a maternidade sem abdicar de outras dimensões da vida (RochaCoutinho, 2005). A maternidade como é vista e vivida na nossa sociedade poderá limitar a vida da mulher, obrigando-a, por vezes, a reajustar os seus objetivos profissionais. Não é suficiente impulsionar a mulher no posto de trabalho, é também necessário fornecer-lhe bases para que ela se consiga manter nessa posição (Balula, 2012).
Considerando a literatura apresentada, o objetivo deste estudo consiste em explorar e descrever a vivência e os significados da liderança feminina e a conciliação deste papel com a maternidade. Decorrem daqui as seguintes Questões de Investigação:

O que significa para uma mulher ser líder? Pretende-se explorar a forma como mulheres que ocupam posições de liderança definem este papel e os significados e representações que the associam, as competências que lhes são requeridas e se experienciam formas de preconceito ou discriminação.

Quais as ambições ou perspetivas das mulheres líderes? Pretende-se identificar as expetativas de mulheres que ocupam posições de liderança, nomeadamente a nível de dimensões nas quais gostariam de introduzir mudança a nível profissional

Como é que as mulheres gerem o papel de líder e a maternidade? Pretende-se explorar a forma como mulheres em posição de liderança conciliam o papel profissional com o papel de mãe e como é que vivem a maternidade na sua relação com um projeto profissional.

\section{MÉTODO}

Realizou-se um estudo qualitativo exploratório e descritivo (Bogdan \& Biklen, 1994), dado que a literatura acerca da problemática focada é escassa e alguns aspetos ainda não foram estudados anteriormente (Sampieri, Collado, \& Lucio, 2006).

\section{Participantes}

Os dados foram recolhidos junto a quatro mulheres líderes numa organização do sector da saúde no Norte de Portugal, numa zona não urbana. $O$ critério de inclusão definido foi serem mães e ocuparem uma posição de liderança, seguindo-se um processo de amostragem por conveniência (Carmo \& Ferreira, 2008). A Tabela 1 caracteriza as participantes.

${ }^{1}$ Reconhecendo a pluralidade nos formatos de família, este estudo considera o modelo tradicional de família (i.e., homem e mulher). 
Tabela 1. Caraterização das participantes

\begin{tabular}{|c|c|c|c|c|}
\hline Participante & 1 & 2 & 3 & 4 \\
\hline Idade & 36 & 36 & 47 & 38 \\
\hline Estado Civil & Casada & Casada & Casada & Casada \\
\hline Habilitações literárias & $12^{\circ}$ & $\begin{array}{l}\text { Licenciatura em } \\
\text { Ciências } \\
\text { Farmacêuticas }\end{array}$ & $\begin{array}{l}\text { Mestrado em } \\
\text { Psicologia do } \\
\text { Idoso }\end{array}$ & $\begin{array}{l}\text { Licenciatura em } \\
\text { Educação de } \\
\text { Infância }\end{array}$ \\
\hline Área/Setor de Atividade & $\begin{array}{l}\text { Coordenadora } \\
\text { de Serviço de } \\
\text { Consulta Externa }\end{array}$ & $\begin{array}{l}\text { Diretora Técnica } \\
\text { de Farmácia }\end{array}$ & $\begin{array}{l}\text { Diretora Técnica } \\
\text { de Área Social }\end{array}$ & $\begin{array}{c}\text { Coordenadora } \\
\text { de } \\
\text { Creche/Pré- } \\
\text { escolar }\end{array}$ \\
\hline $\begin{array}{l}\text { Antiguidade na função de } \\
\text { líder }\end{array}$ & $9 / 10$ anos & 2 anos & 22 anos & 5 meses \\
\hline Número de filhos & 2 & 2 & 2 & 2 \\
\hline Idade dos filhos & 4 e 8 anos & 1 e 5 anos & 16 e 19 anos & $\begin{array}{c}23 \text { meses e } 7 \\
\text { anos }\end{array}$ \\
\hline Número de liderados & $15 / 16$ & 1 & 34 & 17 \\
\hline Género dos liderados & Feminino & Masculino & $\begin{array}{l}30 \text { feminino e } 4 \\
\text { masculino }\end{array}$ & Feminino \\
\hline
\end{tabular}

O desempenho de um cargo de liderança não fazia parte dos planos de carreira de três das participantes ("Nunca pensei na função de líder, nunca pensei "eu sou líder de uma equipa"ll, P3) e duas delas salientam a reticência em aceitar esse cargo: "leu também nunca pensei em ser porque eu não sou muito ambiciosa" (P1), "Não era uma coisa que eu ambicionava e na altura disse mesmo que não.ll (P4). Duas das participantes revelam mesmo um descrédito na possibilidade de se tornarem líderes (P2 e P3): «nunca pensei que conseguisse chegar lá, não é?» (P2). Para P2 este cargo foi, contudo, uma realização pessoal: "Todos nós, acho que perspetivamos isso, não é? Hum, sim gostava muito era uma realização pessoalı. As participantes 1 e 4 alcançaram o cargo através de um desenvolvimento crescente dentro da organização: "(...) entrou outra pessoa (...) passado algum tempo o meu chefe decidiu que eu coordenava o serviço." (P1), "vim para aqui como técnica de Serviço Social, fui promovida a diretora passado um anoll (P3).

Três das participantes foram mães enquanto ocupavam o cargo de líder na organização atual. P4 foi mãe antes de ocupar esta função. No âmbito do estudo as participantes referem-se ao momento em que tiveram os seus filhos, da conciliação após se terem tornado líderes e atualmente.

\section{Recolha da Informação}

Recorreu-se ao método de histórias de vida (Spindola \& Santos, 2003), que permite conhecer o mundo subjetivo e singular de um sujeito, simultaneamente com o seu vivido social, significados e experiências (Poirier, Clapier-Valladon, \& Raybaut, 1999). Falar da própria história é um meio de reviver os acontecimentos que se recorda e é, ao mesmo tempo, um reexperimentar das emoções e sentimentos que estão associados aos mesmos (Brandão, 2007). Este trabalho implica entrevistas repetidas, nas quais deve existir uma forte interação entre entrevistador e entrevistado, que ocorre de forma contínua (Paulilo, 1999). A segunda entrevista, na maioria dos casos, é um reviver da primeira, na medida em que o relembrar do passado pode suscitar recordações, acompanhadas de reflexão acerca de si mesmo, mas também do fenómeno em questão. É, no fundo, aprofundar o que na primeira não foi possível (Poirier et al., 1999). Este método é um 
instrumento privilegiado na medida em que cada entrevista realizada é única e essencial e cada uma é diferente de todas as outras (Paulilo, 1999).

O guião de entrevista utilizado no primeiro momento de recolha de dados é composto por quatro secções: $\left(1^{a}\right)$ introdução: explicita o objetivo do estudo, a forma de recolha de dados e assegura ○ anonimato; (2) caracterização sociodemográfica e profissional da participante; (3) história de vida: questões da vida profissional e pessoal da participante que requerem aprofundamento; (4) fim: conclui-se a entrevista, salientando-se a importância da colaboração da participante. O guião foi validado com recurso a uma entrevista de pré-teste com reflexão falada, junto de uma mulher com as caraterísticas da população-alvo, não sendo necessário introduzir alterações ao mesmo. $\bigcirc$ guião do segundo momento de recolha de dados diferiu para cada participante, uma vez que o seu objetivo era clarificar e/ou aprofundar as informações recolhidas anteriormente. Foi elaborado um protocolo de recolha de dados, sistematizando os dois momentos de recolha de dados. Todas as participantes assinaram o Consentimento Informado.

\section{Procedimentos}

As participantes foram contactadas informalmente, avaliando-se a sua disponibilidade para participar. De seguida foi-lhes enviado um pedido de colaboração formal, por email. As entrevistas foram agendadas consoante a disponibilidade das participantes a nível de tempo e local. No segundo momento de recolha de dados, entrevistada e entrevistadora possuíam uma cópia da transcrição da primeira entrevista, sendo que a da entrevistadora continha notas e questões a explorar. Este procedimento permitiu a ambas o acompanhamento do conteúdo e ideias exploradas na primeira entrevista e do que se pretendia explorar nesta segunda entrevista. Procurou-se que esta segunda entrevista ocorresse num local diferente da primeira, mais informal (e.g., casa da participante), de forma a obter-se uma maior riqueza e profundidade das informações recolhidas. Este procedimento, contudo, nem sempre foi possível.

As entrevistas foram gravadas em formato áudio para uma maior fidelidade dos dados recolhidos e de forma a facilitar a transcrição e análise. As transcrições foram validadas pelas participantes. No primeiro momento de recolha de dados obteve-se a validação das 5 entrevistas; no $2^{\circ}$ momento apenas foi possível obter a validação de 1 entrevista.

\section{Análise da informação}

Os dados foram analisados com recurso à análise de conteúdo temática, considerando os princípios definidos por Bardin (2011). O material resultante das transcrições corresponde ao corpus de análise, tendo-se definido o tema enquanto unidade de significação e segmento de conteúdo (isto é, a unidade de registo). Os dados foram geridos e analisados com o suporte do NVivo 11 (QSR).

O material transcrito foi analisado de forma a garantir que a informação estava conforme ocorreu no momento da entrevista, considerando-se todos os detalhes (Flick, 2005). Num segundo momento realizou-se a leitura flutuante do material transcrito, construindo-se impressões sobre os dados. Posto isto, fez-se uma leitura aprofundada e mais cuidada do material (Bardin, 2011). Para calcular o acordo intercodificador recorreu-se a um segundo codificador, que codificou uma das entrevistas realizadas. Obteve-se uma percentagem de acordo superior a $90 \%$, o que revela uma boa consistência do processo de codificação (Miles \& Huberman, 1994).

\section{APRESENTAÇÃO E DISCUSSÃO DOS RESULTADOS}

\section{O que significa para uma mulher ser líder?}

A liderança é assumida pelas participantes como um cargo que acarreta dificuldades, sendo a conciliação entre a esfera pessoal e profissional uma dessas dificuldades: "Nós quando estamos num cargo de liderança e temos filhos, por exemplo, a vida torna-se um bocado mais complicada, porque lá está temos a nossa vida pessoal e temos este cargoll (P4). Esta dificuldade de conciliação é a mais apontada na literatura (e.g., Abreu, 2016; Alperstedt, Ferreira, \& Serafim, 2014; Candaten, Zanatta, \& Trevisan, 2016), sendo exigente e estando associada a falta de tempo, menor disponibilidade para a família e os filhos, sobrecarga de tarefas, medos e preocupações, stress 
e mau-humor e sentimento de frustração (Candaten et al., 2016). Isto pode originar um sentimento de pressão, que é outra das dificuldades mencionadas por quase todas as participantes. P2, contudo, não se refere a esta dificuldade, talvez por ter apenas um liderado, coordenando um espaço "pequenino", como refere frequentemente.

Conseguir exercer autoridade é outra dificuldade que surge associada ao papel de líder. É interessante notar que as participantes que se referem a esta dificuldade descrevem-se como "mais sensíveis" "(...) eu distribuo - meu trabalho com o meu colega, ou seja, eu partilho, não digo assim: "É para fazer" ou "É à minha maneira")" (P2), "Eu que sou um coração mole, que qualquer coisa me derrete, que tenho dificuldade em bater o pé e dizer é assim: não pode ser como vocês querem, tem que ser... Eu tenho tanta dificuldadel (P4). Uma outra dificuldade prende-se com a partilha da liderança. P4 refere-se a esta dificuldade, sendo a única que iniciou o cargo de líder acompanhada de uma colega com a qual o dividia. Se isso por um lado facilitou a gestão da quantidade de trabalho, graças à divisão de tarefas, por outro lado dificultou-a no que se refere a dar resposta às subordinadas: " quando se tem que dar uma resposta pode-se dar logo na hora, quando estamos duas temos que dizer: "olhe eu vou ver com a minha colega"»l (P4).

Surgem ainda dificuldades associadas às relações com a direção (mencionada por P3) e com os subordinados. As dificuldades a nível do relacionamento entre o género feminino foram as mais verbalizadas, talvez pelo facto das participantes trabalharem maioritariamente com mulheres "A questão é, nós trabalharmos com muitas mulheres, é complicado, nós não agradamos a todos» (P1). Apenas P2 não se refere a dificuldades a este nível, eventualmente por liderar apenas um trabalhador (como se referiu acima), o que poderá facilitar a comunicação entre ambos. Liderar é uma grande responsabilidade e quanto maior o número de liderados, maiores as obrigações a que o líder tem de responder (Miranda, 2012).

Relativamente às competências consideradas necessárias para exercerem o seu cargo de liderança (Quadro 1), a dimensão das relações é entendida como sendo relevante. P2, P3 e P4 sublinham a importância do humanismo e relacionamento interpessoal, competências focadas em diversos estudos acerca da liderança feminina e da liderança eficaz. Moller e Gomes (2010), por exemplo, referem que a liderança feminina é mais centrada nas relações e a que mais valoriza os indivíduos como seres humanos. Por sua vez, Miranda (2012) indica que um líder para se sentir realizado deve tratar as pessoas da forma como gostaria de ser tratado. P 1 e P3 acrescentam como competência básica a gestão de conflitos: «(...) saber mediar (...). Estar aqui como o pêndulo no meio da balança, não é? $E$ saber equilibrar os dois pratos para que não haja conflito, mas os pratos são muitos») (P3). Um líder para ser eficaz deve possuir competências em relações interpessoais, sabendo que o conflito faz parte das diferenças e que $\circ$ diálogo é a solução para o acordo (Oliveira \& Chamarelli, 2013).

Quadro 1. Competências requeridas na liderança.

\begin{tabular}{ll}
\hline Relações & \\
\hline Humanismo e relacionamento & "Não é tudo à minha maneira, mas eu também tenho que ouvir os outros" \\
interpessoal & (P2) \\
(identificado por P2, P3 e P4) & "Temos que ser...que saber estar. Hum, ter respeito pelos outros, não ée Se \\
& de ouvir, hum» (P3) \\
& "Antes de tomarmos (...) qualquer decisão em relação a seja o que for, \\
& temos de nos colocar no lugar da outra pessoa.» (P4) \\
\hline Gestão de conflitos & "às vezes uma situação de conflito, a gente tem que orientá-las» (P1). \\
(identificado por P1 e P3) & "(...) saber mediar entre funcionários e utentes, entre utentes e funcionárias, \\
& entre os funcionários e direção, entre... hum, familias e direção. Estar aqui \\
& como o pêndulo no meio da balança, não é? E saber equilibrar os dois pratos \\
& para que não haja conflito, mas os pratos são muitos.» (P3). \\
\hline Autoridade e liderança & \\
\hline Autoridade & "Eu acho que uma líder tem que se saber impor, não é? Na altura certa, no \\
(identificado por P2 e P4) & momento certo" (P2) \\
& "na liderança tem que mostrar um bocadinho também de autoridade, no \\
& sentido de: é assim, tem que ser assim!» (P4) \\
\hline
\end{tabular}




\begin{tabular}{|c|c|}
\hline \multicolumn{2}{|l|}{ Relações } \\
\hline $\begin{array}{l}\text { Liderar } \\
\text { (identificado por P2) }\end{array}$ & "Não é? Líder, líder não é só saber mandar, não é?» (P2) \\
\hline $\begin{array}{l}\text { Responsabilidade } \\
\text { (identificado por P1, P2 e P3) }\end{array}$ & $\begin{array}{l}\text { "A... responsabilidade acima de tudo, isso é o número um.» (P1) } \\
\text { "De estar cá a tempo inteiro, que era uma coisa que eu não fazia e as } \\
\text { responsabilidades agora são outras, não é? Pronto, porque me são exigidas } \\
\text { mais coisas, não é» (P2) } \\
\text { "eu também tenho mais responsabilidade do que fosse...não quer dizer que } \\
\text { é menos, mas é maior sendo uma diretora" (P3) }\end{array}$ \\
\hline Desenvolvimento & \\
\hline $\begin{array}{l}\text { Aprendizagem contínua } \\
\text { (identificado por P2) }\end{array}$ & $\begin{array}{l}\text { "Quando eu digo que tento dar o meu melhor é nesse sentido... é, quando } \\
\text { não sei tento investigar, tento estudar." (P2) }\end{array}$ \\
\hline Organização & \\
\hline $\begin{array}{l}\text { Competências de organização e } \\
\text { gestão } \\
\text { (identificado por P1, P2 e P3) }\end{array}$ & $\begin{array}{l}\text { "(...) é me exigido que o serviço que seja feito... que seja preciso seja feito } \\
\text { a tempo e horas, simplesmente." (P1) } \\
\text { "e eu tenho que saber geri-la." (P2) } \\
\text { "Tenho que a fazer o melhor que sei e posso, não é?» (P3) }\end{array}$ \\
\hline
\end{tabular}

As questões do exercício da autoridade e do liderar (no sentido de motivar e influenciar outros) também são sublinhadas, sendo ambas apontadas na literatura como relevantes (Miranda, 2012). P2 defende a diferença entre liderar e chefiar, o que vai ao encontro da ideia que a quem ocupa posições de chefia "não basta apenas mandar, tem que saber liderar" (Miranda, 2012, p.51). Quase todas as participantes (exceto P4) consideram fundamentais as competências de organização e gestão do negócio, competências que são muitas das vezes desenvolvidas pelas mulheres através da experiência das tarefas domésticas, que se revelam uma mais valia no local de trabalho (Nogueira, 2006). Efetivamente, algumas das participantes assemelharam a sua liderança à gestão da casa.

Relativamente à vivência de discriminação, as análises apontam que algumas participantes já experienciaram atitudes sexistas. P3 revela ter vivenciado na sua carreira assédio moral: "l...todos os dias, nós como mulheres, não eramos bem tratadas. Tem de haver respeito. Não sei se agora há, na altura não havia. Também fui vítima um bocadinho disso e a minha vontade de sair foi por causa dissoll. A mesma participante revela ter sido alvo de assédio sexual: "Assédio tentado comigo e concretizado com algumas funcionárias e eu sabia disso porque elas desabafavam comigo e eu não conseguia viver com issoll. O assédio moral e sexual sobre as mulheres são fenómenos comum nas organizações (Dias, 2008, 2014) e os agressores utilizam a sua posição para chantagear com fins pessoais (Freitas, 2001), conforme revela P4: Uera uma pessoa com responsabilidade na estrutura, muita responsabilidade atéll. Apesar de estas vivências não terem ocorrido na organização atual onde se insere a participante, esta exercia um cargo de liderança quando foi alvo destas formas de descriminação. Tratava-se, aliás, de algo experienciado de forma geral na organização: "Não interessa se sou administrativa, se sou empregada de limpeza, no caso tudo serviall. Sublinhe-se ainda que as participantes observam atitudes possessivas de homens em relação a mulheres subordinadas. De forma específica, as participantes referem-se à pressão que alguns homens exercem sobre as suas companheiras: "Existe ainda muito pouca liberdade de movimentos, pouca confiança, muita desconfiança da parte masculina, da relação ao trabalho, por exemplo há... quando... elas trabalham por turnos, não é? II. Isto leva a inferir que o preconceito e a discriminação mais do que estarem associados ao cargo, estão associados ao género - ser-se mulher e ao enraizamento de uma cultura machista (Stawinski \& From, 2016). Note-se que os dados foram recolhidos numa zona não urbana, onde os estereótipos poderão, eventualmente, modificar-se mais lentamente quando comparado com as zonas urbanas.

P2 tem a perceção de desigualdade salarial na liderança, não confirmando este tipo de discriminação formal na sua organização "Lá está, eu não as sinto. Mas é lógico que nós sabemos que 
as há, não é?ll. As participantes referem a ausência de discriminação, vivida ou observada, dentro das instituições e no cargo atual: "(...) no meu serviço nunca senti nenhuma diferença. Nunca, nunca.» (P1), "(...) muito bem tratadas, muito bem tratadas aqui. Atentas, preocupadas, educação e respeito.l” (P3). Apesar de defenderem que não sentem qualquer discriminação no seu cargo atual, as participantes consideram que esta é uma realidade, o que parece traduzir um paradoxo.

\section{Quais as ambições ou perspetivas das mulheres líderes?}

As ambições das mulheres lideres estudadas prendem-se com melhorar condições de trabalho; desenvolver competências; desenvolver a capacidade de gestão de conflitos; permanecer ou não num cargo de líder; e tornar-se empreendedora.

Há referência a um horário de trabalho mais flexível e mais tempo para a vida pessoal. Conciliar a vida profissional e a vida pessoal é, efectivamente, uma tarefa difícil e exigente para as mulheres (Abreu, 2016; Candaten et al., 2016). Abreu (2016) refere que normalmente as líderes para vencerem a desconfiança que ainda existe nas suas capacidades, acabam por trabalhar mais horas do que os homens, o que pode prejudicar o tempo despendido para a vida pessoal e levar a um sentimento de pressão associado ao cargo de liderança, tal como se observou ao discutir os resultados à QI1. Há também o desejo de um salário adequado à função: "Gostava de ter um aumento para o trabalho que faço..." (P1).

De acordo com P1 e P4 são também necessárias melhorias no espaço de trabalho: "Que o nosso espaço fosse maior, porque o nosso serviço é pequeno para a quantidade de coisas que temos, isso assim a nível de espaço era necessáriol) (P1). P3 refere aida o desejo de mais tempo para trabalho prático "gostava de ter mais tempo para os idosos, mas como estou muito assoberbada de outras tarefas burocráticas que são necessárias também fazer I. As condições de trabalho (como as referidas) são aspetos que contribuem diretamente para a satisfação dos colaboradores numa organização (Tamayo, 1998, 2000).
Uma segunda expectativa prende-se com o desenvolvimento de competências, tendo sido apontadas competências de liderança e técnicas. A aprendizagem da liderança ocorre a três níveis: sobre si mesmo, sobre o outro e sobre o contexto (Vergara, 2007). Desenvolver a capacidade de gestão de conflitos é outra das competências a ser trabalhada: "Ainda recentemente tive numa formação (...) sobre esta questão de relacionamento interpessoal e gestão de conflitos porque eu tenho de estar sempre preparada para lidar com estas coisas e também tenho vontade de aprender e de inovar.l (P3). Ainda no campo relacional, $\mathrm{P} 1$ refere-se à necessidade de melhor gerir a voz: «Porque eu sou constantemente chamada à atenção. Constantemente... pelo menos nas avaliações, que eu que falo muito alto. Mas isso é do meu temperamento. $E$ o que eu acho que poderia melhorar seria issoll. Já P4 refere a necessidade de aprender a exercer autoridade: "Í mesmo isso (...) Ser um bocado mais dura, mais exigentell, dificuldade apontada anteriormente e reconhecida agora como uma competência a trabalhar. As competências de formação técnica estão relacionadas com os aspetos que as participantes necessitam de trabalhar na sua área de atuação: "Toda aquela parte que é no bloco (...) eu aí noto (...) que precisava de muita formação" (P2), "Acho que tenho que investir mais na questão da... do conhecimento e na forma como agir com, com os idosos faz-me... por causa das demências e da, da doença do foro mental como começam a aparecer muito, não é? $E$ da dependência, isso eu tenho de investir aíll (P3).

Uma outra expetativa prende-se com a vontade de permanecer ou não num cargo de líder (Quadro 2), observando-se que as participantes 1, 2 e 3 têm essa vontade. Isso poderá significar que apesar de não terem perspetivado ocupar um cargo de liderança, este agora inclui-se nas suas expetativas profissionais. Contudo, não descartam a hipótese de exercer outro cargo, caso não tenham a possibilidade de escolha. P4 contraria esta ideia, assumindo que não procuraria um cargo de liderança em caso de deixar o cargo actual. De notar que esta participante é a que se encontra há menos tempo no cargo (5 meses), o que poderá ter influenciado a sua resposta, encontrando-se ainda num processo de adaptação a uma posição organizacional desafiante. 
Desinteresse em mudar de emprego (identificado por P1)

"Ai fora do hospital...a nível profissional não...já pensei aqui há uns...já há muito tempo atrás mudar de emprego mas...porque andava aí chateada com umas situações que ocorreram cá mas a nível de trabalho e de emprego não é fácil, não está mesmo nada fácil e...como gosto do que faço, não trocava agora. Agora não trocava.» (P1)

\begin{tabular}{ll}
\hline $\begin{array}{l}\text { Mesma área de atividade } \\
\text { (identificado por P2 e P4) }\end{array}$ & $\begin{array}{l}\text { "Não. Eu se... é assim, se eu deixasse aqui, eu procuraria em farmácia (pausa) } \\
\text { outra vez, porque é uma área que eu gosto... que eu gosto imenso» (P2) }\end{array}$ \\
\hline $\begin{array}{l}\text { Não procuraria um cargo de liderança } \\
\text { (identificado por P5) }\end{array}$ & "Ser líder de... Muito sinceramente não." (P4) \\
\hline $\begin{array}{l}\text { Optaria por cargo de liderança } \\
\text { (identificado por P1, P2 e P3) }\end{array}$ & $\begin{array}{l}\text { "Atrás, não. Percebe? Eu para sair daqui tenho que ir para uma coisa igual, } \\
\text { empregada porque acho que, pronto, mas se tiver que ser, irei.» (P2) }\end{array}$ \\
\hline $\begin{array}{l}\text { Sem possibilidade de escolha } \\
\text { (identificado por P1, P2 e P3) }\end{array}$ & $\begin{array}{l}\text { "É assim, se tivesse de procurar não tinha obrigatoriamente que ser, porque nós } \\
\text { infelizmente precisamos de trabalhar para pagar as nossas contas e se tivesse }\end{array}$ \\
& que ser..." (P1)
\end{tabular}

Uma outra expetativa prende-se com a ambição de empreender, referida por P2, que conciliaria com o seu emprego atual: "Uma coisa que eu sei que, ok, estou cansada dali, tenho aqui outra coisa. Pronto. (...) Eu gostava de ter uma coisinha minha. Um sonho meu só. (...) É uma realização, é só. Depois porque quero outra experiência. Era... era outro desafio, 'tá bem? Quando vim para aqui era um desafio novo. Tudo o que havia lá fora para conquistar já tinha conquistado. Aqui não, era um desafio novo. $E$ depois agora é esse bichinho, queria ter uma coisa minha?»l. O desejo de realização profissional, a busca por desafios, a fuga da rotina e o desejo de trabalhar por conta própria são reconhecidos enquanto motivos para 0 empreendedorismo (Vicenzi \& Bulgacov (2013). Distinguem-se, contudo, das ideias de Munhoz (2000) e Amorim e Batista (2012), que apontam como motivações para as líderes empreenderem a desigualdade de género e a dificuldade em ascender ou manter a sua posição nas organizações.

Relativamente às expetativas em relação ao cargo atual, as participantes mostram vontade de continuar a realizar um bom trabalho ( $1 \mathrm{Em}$ relação à instituição gostava de... (pausa) que fosse reconhecida se calhar com o trabalho, mas que fosse reconhecida mesmo porque sou boa naquilo que façoll, P2) e de permanecer na mesma atividade ou organização, o que reforça a leitura que os objetivos das participantes passam por investir na carreira de líder ("Gostava de ter mais tempo para isso, gostava de implementar outras coisas aqui (...) mais gente para cuidar melhor I, P3). P2 espera no futuro ser reconhecida pelo seu trabalho, percebendo-se que esse reconhecimento não tem acontecido até ao momento. A ausência de elogios do superior, a ausência de críticas construtivas e a falta de reconhecimento do trabalho indicam que existem falhas na comunicação entre líderes e liderados, o que tem impacto negativo nos liderados (Santos \& Silva, 2003).

\section{Como é que as mulheres gerem o papel de líder e a maternidade?}

P1, P3 e P4 não ponderaram o adiamento da maternidade: "(...) adiar a maternidade por causa da carreira, isso não. Não, o trabalho é importante, mas a nossa vida familiar também é.ll (P1). P1 e P3 ponderaram a interrupção temporária da carreira: "(...) enquanto as minhas filhas fossem pequenas, se eu pudesse, se eu tivesse estabilidade económica se calhar estava, tipo um ano ou dois enquanto elas eram mais pequenas e depois ia trabalhar.川 (P1). Isto vai ao encontro do estudo de Rocha-Coutinho (2005), que aponta que as mulheres que querem investir mais na maternidade desinvestem ou abandonam (temporária ou definitivamente) a sua carreira profissional. P2, por sua vez, adiou a maternidade para não prejudicar a entidade patronal: Ileu achava que se calhar engravidar e depois ir para casa seria menos um funcionário e aí seria... um prejuízo para eles no fundo, não é? Porque era menos uma pessoa a trabalhar. Pronto, então adiei por um ano, prontoll. Isto corrobora o estudo de Beltrame e Donelli (2012). 
No que diz respeito à interferência da maternidade na vida profissional, as participantes referem ter tido um afastamento temporário do cargo na altura da gravidez e salientam uma ausência de constrangimentos na conciliação destes dois papéis: "porque apesar de vez em quando nos queixarmos, mas as coisas dão bem para conciliar» (P4). P4 indica que este papel a ajudou à realização de um melhor trabalho, uma vez que a sua área de atividade é com crianças: "la maternidade também me ajudou na minha profissão, no sentido de... eu ter experiências pessoais que me fizeram ver com outros olhos situações que os pais me falavam (...) ). A literatura sublinha os aspetos positivos da maternidade na vida profissional, salientando que as mulheres ganham uma maior motivação e preocupação em realizar bem o seu trabalho, essencialmente porque a partir do momento em que são mães têm alguém que depende delas (Rocha-Coutinho, 2005).

Aconciliação do papel de líder e a maternidade implica - recurso a algumas estratégias, nomeadamente, a divisão das responsabilidades entre os conjugues no cuidado dos filhos e no transporte para as atividades. Todas as participantes fazem referência à divisão no cuidado dos filhos: «Pronto, nós sempre nos ajudamos, sempre demos banho juntos às pequenas. A nível de comida se eu precisasse (...) se eu não estivesse disponível ele dava ou até enquanto eu fazia para nós ele dava à menina" (P1), "(...) Ele em casa ajuda-me, não é? Quando está, ajuda-me ao final do dia com os banhos, com... pronto, essa... ajuda-mell (P4). A responsabilidade pelo transporte dos filhos é também divida, de acordo com P1 e P2: «Nunca me preciso de preocupar em ir buscá-la à escola, porque - pai vai buscá-la, tenho é que sempre me preocupar em ir buscar a mais pequena, ou seja, eu vou buscar a pequena, o pai vai buscar a grande. Dividimos!» (P1). Estes dados corroboram Aboim (2010), quando refere que os homens têm vindo a entrar no domínio doméstico à medida que determinadas tarefas domésticas e parentais se conjugalizam, isto é, passam a ser partilhadas pelo casal. Todavia, importa refletir acerca do termo usado pela maioria das participantes - "ajuda-me" - contrariamente a uma divisão de tarefas/responsabilidades, o que poderá denunciar uma responsabilidade maior para as mulheres com as atividades domésticas e com os filhos, tal como apontado na literatura (e.g., Quadrelli, 2016).
Outro aspeto identificado são as redes de apoio, que têm permitido à mulher conjugar a maternidade e a vida profissional (Almeida, 2007; Souza et al., 2011 1). P1 e P4 recorrem a avós e a creches quando nenhum dos elementos do casal pode ficar com os filhos. P2 também recorre aos avós: "los meus pais, pessoas que me ajudam, para que muitas das vezes possa ficar aqui a trabalhar até mais tardell. Apesar dos homens já terem entrado na esfera doméstica, conforme referido, a sobrecarga feminina ainda é evidente na maioria das famílias (Aboim, 2010). Aboim sublinha que a mulher realiza mais de metade das tarefas domésticas sem o apoio do conjugue, conforme se percebe no discurso das participantes: "E depois é... em casa é tudo o resto, é a educação, é os banhos, é a alimentação, é tudo, é pôr a dormir, é organizar a casa, porque... não é? Eu sou... que sou mãe e sou dona da casa e tenho tudo em casa para organizar, pronto. Mas consegue-se, desde que esteja tudo mais ou menos pré-definido.ll (P2). Esta sobrecarga tem consequências: "(..) fico mais cansada, não é? É lógico que ando sempre a correr (...) Chego sempre atrasada a tudo» (P2). E reforça a dificuldade na conciliação trabalho-família: "Ser líder e ser mãe ao mesmo tempo (...). É um bocado complicado conseguir separar, nós tentamos fazê-lo ao máximo da melhor forma (...) mas é complicadol» (P4), "As contas para pagar, a casa para tomar conta, jantares, almoços, roupas para passar, limpezas, mesmo que o marido nos ajude a responsabilidade cai sempre na mulher ॥ (P1). Conciliar as obrigações familiares pelas quais a mulher ainda se sente responsável e ao mesmo tempo ter um bom desempenho no trabalho é altamente desgastante para a carreira de qualquer mulher (Rocha-Coutinho \& Coutinho, $2011)$. Este facto pode desafiá-la para um maior investimento na maternidade ou a trabalhar para a preservação da carreira profissional, ou, quando possivel, de forma a conciliar os dois.

Devido às exigências do cargo quase todas as participantes (exceto $\mathrm{P} 1$ ) admitem possuir menor disponibilidade de recursos para a vida familiar: " $E E$ diferente. Agora com a coordenação é mais cabeça, é trazer a cabeça cheia para casa, essa foi a grande diferença e que muitas vezes, coitados dos meus filhos, acabam por ouvir uma má resposta ou uma...porque estamos com a cabeça cheia com problemas de lá.ll (P4). Este aspeto vai ao encontro da literatura que aponta que o desgaste associado à vida profissional 
poderá originar níveis mais baixos de energia e disponibilidade para a vida familiar (Matias, Andrade, \& Fontaine, 2011).

\section{CONCLUSÕES}

As histórias de vida apresentadas neste estudo revelam que o cargo de líder não foi planeado por estas mulheres, surgindo com o crescimento dentro da organização ou com a saída de um líder. Apesar disso revelou-se para algumas delas uma realização pessoal e um desafio novo. Sabe-se que este é um cargo exigente, que implica um grande esforço, gerir dificuldades e investir no desenvolvimento contínuo de competências, o que leva a refletir sobre a aceitação ou não desta responsabilidade (Miranda, 2012). Os resultados permitem perceber que as participantes reconhecem a existência de estereótipos que defendem que a liderança feminina é inferior à masculina, que a mulher possui um lado emocional mais frágil, ao mesmo tempo que se exige mais dela. A maternidade parece permanecer como uma dimensão que pode dificultar o percurso profissional da mulher, por culturalmente as responsabilidades a este nível ainda the serem maioritariamente atribuídas.

Algumas das líderes já vivenciaram ou observaram formas de preconceito ou discriminação na sua carreira, tendência que a literatura refere (Kanan, 2010; Nogueira, 2006). A vivência e a observação de situações de assédio moral e sexual a nível das subordinadas permitem inferir que $\circ$ preconceito $e$ a discriminação não estão diretamente ligados ao cargo exercido, mas ao género (i.e., ser-se mulher) e leva a perceber que ainda se vive numa cultura machista, que se vai dissipando muito lentamente (Stawinski \& From, 2016). O preconceito parece não ser vivido atualmente pelas participantes, mas estas denunciam diferenças (no salário, formas de tratamento) e identificam-no nas relações de subordinadas com os seus parceiros. Poderse-á, contudo, colocar a possibilidade de as participantes terem adotado, eventualmente, uma postura protetora em relação à sua organização de pertença. Conclui-se, ainda, que a discriminação informal parece predominar em relação à discriminação formal.
Relativamente às expetativas que as líderes projetam para a vida profissional, encontram-se a melhoria de condições de trabalho (e.g., salário) e, o desenvolvimento de competências de liderança e técnicas. Isto vai ao encontro da literatura que aponta que a aprendizagem da liderança é um processo contínuo que precisa de ser desenvolvido (Vergara, 2007). No geral as líderes estudadas demonstram vontade em continuar no mesmo cargo ou organização, investindo no seu crescimento e desenvolvimento profissional. Demonstram vontade em continuar a liderar, mesmo quando não perspetivaram este cargo para a sua carreira. $O$ empreendedorismo também surge enquanto uma expectativa, motivada por uma busca de novos desafios, como escape da rotina e o desejo de se realizar profissionalmente (Vicenzi \& Bulgacov, 2013).

Os dados sugerem que apesar do homem já realizar algumas tarefas domésticas e cuidar dos filhos, a mulher ainda é sobrecarregada com responsabilidades a este nível. As participantes referem-se ao homem enquanto um "ajudante", o que leva a deduzir que as responsabilidades familiares ainda não são distribuídas equitativamente e que os papéis de género tradicionais prevalecem. A conciliação do papel de líder e de mãe requer um elevado esforço das mulheres. Apesar da sobrecarga vivenciada, que provoca dificuldades na conciliação trabalho-família, cansaço e menor disponibilidade para a vida pessoal e familiar, as líderes não colocam a hipótese de abandonar a sua carreira. Aliás, para elas, tanto a maternidade como a carreira profissional são aspetos que dão um sentido de completude às suas vidas, conforme aponta a literatura (Rocha-Coutinho \& Coutinho 2011). Apesar de ser uma conjugação difícil, consideram que é possível. Importa também refletir acerca do facto das mulheres associarem a maternidade a uma motivação extra para realizar um melhor trabalho, sendo que o tempo disponível para conciliar o trabalho e a maternidade/vida pessoal revela-se o grande obstáculo.

Este estudo apresenta algumas limitações. $O$ facto de a investigadora possuir um contacto próximo com a organização de pertença das participantes, ainda que não tenha tido contacto com elas anteriormente à recolha de dados, pode ter influenciado o discurso das participantes, no sentido de salvaguardarem o 
seu cargo ou a organização. Contudo, de forma a que as participantes se enquadrassem nos critérios de inclusão definidos foi necessário recorrer a uma amostragem por conveniência. Um outro aspeto sobre o qual importa refletir é o facto de no segundo momento de recolha de dados apenas uma das participantes ter validado a entrevista. Esta situação poderá estar associada ao facto de o pedido de validação ter ocorrido em julho, tipicamente um mês de férias, pelo que as participantes poderão não ter estado tão disponíveis para colaborar. Esta validação, contudo, teria enriquecido o estudo.

Este estudo foca a perspetiva de casais heterossexuais com filhos. Futuras investigações deverão integrar o surgimento de novos modelos familiares e as novas formas de conjugalidade e parentalidade (Rodriguez \& Gomes, 2012). Também seria interessante investigar as vivências da liderança feminina em mulheres solteiras e casadas e/ou com filhos/sem filhos, conforme sublinhou uma das participantes ${ }^{2}$. Seria igualmente pertinente aceder às representações de homens acerca da forma como mulheres lideres conciliam os desafios da sua função com a maternidade.

Espera-se que este estudo contribua para a sensibilização da importância da igualdade de oportunidades e para a complementaridade de géneros no mercado de trabalho. É necessário mostrar que homens e mulheres desempenham um papel fundamental para o alcance da eficácia das organizações portuguesas, num ambiente que se revela cada vez mais exigente e complexo. Esperase ainda que a sistematização das experiências das mulheres aqui estudadas contribua para a mudança dos papéis de género tradicionais, promovendo a partilha das responsabilidades domésticas e familiares no casal, de forma a aliviar a pressão exercida sobre as mulheres.

\section{CONFLITOS DE INTERESSES:}

Nenhum conflito financeiro, legal ou político envolvendo terceiros (governo, empresas e fundações privadas, etc.) foi declarado para nenhum aspecto do trabalho submetido (incluindo mas não limitandose a subvenções e financiamentos, conselho consultivo, desenho de estudo, preparação de manuscrito, análise estatística, etc).

\section{REFERÊNCIAS}

Wall, K., Aboim, S., \& Cunha, V. (Coords.). (2010). Género, família e mudança em Portugal. In K. Wall, S. Aboim, \& V. Cunha (Coords.), A vida familiar no masculinonegociando velhas e novas masculinidades (Cap.1, p. 39-66). Lisboa: Comissão para a Igualdade no Trabalho e no Emprego.

Abreu, K. (2016). Os Desafios da Liderança Feminina no Ambiente Corporativo. Revista Eletrônica SPEI, 2(3), 1-24.

Almeida, L. S. (2007). Mãe, Cuidadora e Trabalhadora: As múltiplas identidades de mães que trabalham. Revista do Departamento de Psicologia, 19(2), 411 422. Recuperado de http://www.scielo.br/scielo. php?pid=S0 $104-80232007000200011$ \&script $=$ sci abstract\&tlng=pt. doi: $10.1590 / \mathrm{S0104-}$ $\underline{80232007000200011}$

Alperstedt, G. D., Ferreira, J. B., \& Serafim, M. C. (2014). Empreendedorismo Feminino: dificuldades relatadas em histórias de vida. Revista de Ciências da Administração, 16(40), 221 - 234. Recuperado de https://periodicos.ufsc.br/index.php/adm/ article/view/2175-8077.2014v16n40p221. doi: $10.5007 / 2175-8077.2014 v 16 n 40 p 221$

Amorim, R. O., \& Batista, L. E. (2012). Empreendedorismo feminino: razão do empreendimento. Núcleo de Pesquisa da Finan., 3(3), 1-13. Recuperado de http://uniesp.edu.br/sites/_biblioteca/ revistas/20170602115149.pdf

Balula, P. A. A. G. (2012). Perspectivas e contributos de uma liderança no feminino (Dissertação de mestrado). Universidade Católica Portuguesa, Centro Regional das Beiras, Pólo de Viseu, Viseu, Portugal. Recuperado de http://repositorio.ucp.pt/ bitstream/10400.14/15462/1/Tese \%20de \%20 Mestrado\%20-Perspectivas $\% 20$ e $\% 20$ Contributos $\% 20$ de $\% 20$ uma $\% 20$ Lideran $\%$ C3\%A7a $\% 20$ no $\% 20$ Feminino\%20-\%20Paula\%20Balula.pdf

Bardin, L. (201 1). Análise de conteúdo (4a ed.). Lisboa: Edições 70.

Beltrame, G. R., \& Donelli, T. M. S. (2012). Maternidade e carreira: desafios frente à conciliação de papéis. Aletheia, (38-39), 206-217. Recuperado de http://pepsic.bvsalud.org/scielo.php?script=sci_ abstract\&pid=S1 413-03942012000200017

Bogdan, R. C., \& Biklen, S. K. (1994). Investigação qualitativa em educação: Uma introdução à teoria e aos métodos. Porto: Porto Editora.

2 Participante 3 , a quem se agradece a reflexão. 
Brandão, A. M. (2007). Entre a vida vivida e a vida contada: a história de vida como material primário de investigação sociológica, Configurações, 3, 83-106.

Candaten, D. M., Zanatta, J. M., \& Trevisan, J. K. D. V. (2016, março). Mulheres Empreendedoras: os desafios para equilibrar a vida pessoal e profissional. Encontro de Estudos sobre Empreendedorismo e Gestão de Pequenas Empresas. Passo Fundo, RS, Brasil, 9. Recuperado de http://egepe.org.br/anais/arquivos/edicaoatual/ Artig0507.pdf

Carmo, H., \& Ferreira, M. M. (2008). Metodologia da Investigação - Guia para Auto-Aprendizagem (2a edição). Lisboa: Universidade Aberta.

Cotter, D. A., DeFiore, J., Hermsen, J.M., Kowalewski, B. M., \& Vanneman, R. (1997). All Women Benefit: The MacroLevel Effect of Occupational Integration on Gender Earnings Equality. American Sociological Review, 62(5), 714-734. Recuperado de https://www.jstor.org/ stable $/ 2657356$ ? seq = 1 \#page_scan_tab_contents

Dias, I. (2007). Família e trabalho feminino: o género das desigualdades. Ex aequo: Revista da Associação Portuguesa de Estudos sobre as Mulheres, 15, 149 166. Recuperado de https://repositorio-aberto.up.pt/ handle/10216/25432

Dias, I. (2008). Violência Contra as Mulheres no Trabalho: O caso do assédio sexual. Sociologia, problemas e práticas, 57, 11-23. Recuperado de http:// www.scielo.mec.pt/scielo.php?pid=S0873$65292008000200002 \&$ script=sci_abstract

Diniz, D. (2004, julho 29). As faces da ambição feminina. Revista Exame. 823, 1-9.

Downes, M., Hemmasi, M., \& Eshghi, G. (2014). When A Perceived Glass Ceiling Impacts Organizational Commitment And Turnover Intent: The Mediating Role Of Distributive Justice. Journal of Diversity Management, 9(2), 131-146. Recuperado de https:// www.cluteinstitute.com/ojs/index.php/JDM/article/ view/8971. doi: 10.19030/idm.v9i2.8971

Duarte, A., D'Oliveira, T., \& Gomes, J. (2009). Imperium femininis...: Uma liderança de sucesso escondido. Revista Portuguesa e Brasileira de Gestão, 8(3), 12-24. Recuperado de http:// www.scielo.mec.pt/scielo.php? script $=$ sci arttext\&pid $=$ S1 645-44642009000300002

EUROSTAT. (2017, março 8). Do women still earn less than men?. Recuperado de http://ec.europa.eu/eurostat/ web/products-eurostat-news/-/DDN-20170307-1

Ferreira, J. M. C., Neves, J. G., \& Caetano, A. (2001). O processo de liderança. In Ferreira, J. M. C., Neves, J. G., \& Caetano, A. Manual de psicossociologia das organizações (Cap.14, p.377-403). Amadora: McGraw-Hill.

Flick, U. (2005). Métodos Qualitativos na Investigação Científica. ( 1 a ed.). Lisboa: Monitor.

Fontenele-Mourão, T. M. (2006). Mulheres no topo de carreira: Flexibilidade e Persistência. (p.1-92). Brasília: Secretaria Especial de Políticas para as Mulheres.

Freitas, M. E. (2001). Assedio moral e assedio sexual: faces do poder perverso nas organizações. Revista de Administração de Empresas, 41 (2), 8-19. Recuperado de http://www.scielo.br/scielo.php?script=sci_ arttext\&pid=S0034-75902001000200002. doi: $10.1590 / 50034-75902001000200002$

Gonçalves, M. H. S. (2011). A articulação trabalho-família vivenciada por gestoras portuguesas: uma fonte de stresse ocupacional? (Dissertação de mestrado). Faculdade de Psicologia e de Ciências da Educação, Universidade do Porto, Porto, Portugal. Recuperado de https://sigarra.up.pt/fdup/pt/pub_geral.pub_ view?pi_pub_base_id $=29548$

Guerreiro, M. D., Lourenço, V., \& Pereira, I. (2006). Boas Práticas de Conciliação entre Vida Profissional e Vida Familiar. Manual para as Empresas (4a ed., p. 1-52) Lisboa: Comissão para Igualdade no Trabalho e no Emprego. Recuperado de http://www.igualdade.cmabrantes.pt/docs/Boas_Praticas_de_Conciliac.pdf

Kanan, L. A. (2010). Poder e liderança de mulheres nas organizações de trabalho. Organizações \& Sociedade, 17(53), 243-257. Recuperado de https://portalseer. ufba.br/index.php/revistaoes/article/view/11104

Knudsen, K. (2009). Striking a different balance Workfamily conflict for female and male managers in a Scandinavian context. Gender in Management: An International Journal, 24(4), 252-269.

Recuperado de http://www.emeraldinsight.com/ doi/full/10.1108/17542410910961541. doi: $10.1108 / 17542410910961541$

Lopes, D., \& Brandão, C. (2017). Liderança no feminino: um estudo com recurso a histórias de vida. Atas Congresso Ibero-Americano em Investigação Qualitativa. Salamanca, Espanha. 6. Recuperado de http:// proceedings.ciaiq.org/index.php/ciaiq2017/article/ view/1167

Manning, T. T. (2002). Gender, managerial level, transformational leadership and work satisfaction. Women in Management Review, 17(5), 207-216. doi: $10.1108 / 09649420210433166$

Matias, M., Andrade, C., \& Fontaine, A. M. (2011). Diferenças de género no conflito trabalho- 
família: um estudo com famílias portuguesas de duplo-emprego com filhos em idade préescolar. Psicologia, XXV(1), 9-32. Recuperado de http://www.scielo.mec.pt/scielo.php?script=sci_ arttext\&pid=S0874-20492011000100001

Miles, M. B., \& Huberman, A. M. (1994). Qualitative data analysis: An expanded sourcebook. (2a ed.) London: Sage Publications.

Miranda, A. L. C. (2012). Liderança Empresarial: O desafio de ser líder nas organizações (Trabalho de conclusão de curso). Instituto Municipal de Ensino Superior de Assis, Assis, SP, Brasil.

Moller, M. A. B., \& Gomes, J. F. S. (2010). Quid Vincit? O impacto da liderança feminina na implicação organizacional. Análise Psicológica, 28(4), 683-697. Recuperado de http://publicacoes.ispa.pt/index.php/ ap/article/view/389. doi: 10.14417/ap.389

Munhoz, G. S. (2000, outubro). Quais as contribuições que o estilo feminino de liderança traz para as organizações empreendedoras. Anais do Encontro de Estudos sobre Empreendedorismo e Gestão de Pequenas Empresas, Maringá, PR, Brasil, 1. Recuperado de http:// www.anegepe.org.br/edicoesanteriores/maringa/ GPE2000-01.pdf

Neto, A. M. C., Tanure, B., \& Andrade, J. (2010). Executivas: Carreira, maternidade, amores e preconceitos. RAE-eletrônica, 9(1), 1-24. Recuperado de http://www.scielo.br/scielo.php?pid=S1676$56482010000100004 \&$ script=sci_abstract\&tlng=pt. doi: $10.1590 /$ S1676-56482010000100004

Nogueira, M. C. O. C. (2006). Os discursos das mulheres em posições de poder. Cadernos de Psicologia Social do Trabalho, 9(2), 57-72. Recuperado de http:// www.revistas.usp.br/cpst/article/view/25965. doi: 10.11606/issn.1981-0490.v9i2p57-72

Oliveira, J. C., \& Chamarelli, J. (2013). Liderança Situacional: Eficácia da Liderança do Gestor de Recursos Humanos. Cognitio/Pós-Graduação Unilins, (1), 1-18. Recuperado de http://revista.unilins.edu.br/index. php/cognitio/article/view/39

Paulilo, M. Â. S. (1999). A pesquisa qualitativa e a história de vida. Serviço social em revista, 2(1), 135-148. Recuperado de http://www.uel.br/revistas/ssrevista/ n1v2.pdf

Perista, H. (2016, junho 28). Elas trabalham mais que eles. E $70 \%$ das mulheres dizem que é justo o trabalho que fazem em casa. Observador. Recuperado de http:// observador.pt/2016/06/28/elas-trabalham-maisque-eles-e-70-das-mulheres-dizem-que-e-justo-otrabalho-que-fazem-em-casa/
Pinheiro, R. S., Batista, T. S., \& Freitas, B. S. A. (2014). Um estudo sobre a gestão feminina: desafios, conquistas e representações. Anais do Simpósio de TCC. Brasília, DF, Brasil. Recuperado de http://nippromove.hospedagemdesites.ws/ anais_simposio/arquivos_up/documentos/ artigos/9ccca89d882fd221a05b 11 f01 1369396.pdf

Poirier, J., Clapier-Valladon, S., \& Raybaut, P. (1999). Histórias de Vida: teoria e prática (2a ed.). Oeiras: Celta Editora.

Probst, E. R., \& Ramos, P. (2003). A evolução da mulher no mercado de trabalho. Instituto Catarinense de Pós-Graduação, 1-8. Recuperado de http://www. posuniasselvi.com.br/artigos/rev02-05.pdf

Quadrelli, I. P. (2016). Vai ter coragem? Uma descrição fenomenológica da relação entre maternidade e trabalho (Dissertação de mestrado). Universidade Católica de Brasília, Brasília, DF, Brasil. Recuperado de https://bdtd.ucb.br:8443/ispui/handle/ tede/2086

Rocha-Coutinho, M. L. (2005). Variações sobre um antigo tema: a maternidade para as mulheres. In Féres-Carneiro, T. Família e casal: efeitos da contemporaneidade (pp. 122-137). Rio de Janeiro: PUC-Rio.

Rocha-Coutinho, M. L., \& Coutinho, R. R. (2011). Mulheres brasileiras em posições de liderança: Novas perspectivas para antigos desafios. Economia Global e Gestão, 16(1), 61-79. Recuperado de http://www.scielo.mec.pt/scielo.php?script=sci_ arttext\&pid=S0873-74442011000100005

Rodriguez, B. C., \& Gomes, I. C. (2012). Novas formas de parentalidade: do modelo tradicional à homoparentalidade. Boletim de Psicologia, 62(136), 29-36. Recuperado de http:// pepsic.bvsalud.org/scielo.php?script $=$ sci_ arttext\&pid=S0006-59432012000100004

Sampieri, R. H., Collado, C. F., \& Lucio, M. P. B. (2006). Metodologia de Pesquisa. (3a ed.). São Paulo: McGraw-Hill.

Santos, J. C. S. D., \& Antunes, E. D. D. (2012). Relações de Gêneros nas Organizações: a construção de estereótipos de liderança masculina e feminina no judiciário de Rondônia. Revista de Administração e Negócios da Amazônia, 4(3), 171-189. Recueprado de http://www.periodicos.unir.br/index.php/rara/ article/view/570

Santos, K. M. A. B., \& Silva, M. J. P. (2003). Comunicação entre líderes e liderados: visão dos enfermeiros. 
Revista da Escola de Enfermagem da USP, 37(2), 97 108. doi: $10.1590 /$ S0080-62342003000200012

Silva, M. P. (2014). Mulher e poder: percepções de líderes femininas nas organizações (Trabalho de conclusão de curso). Faculdade de Arquitetura, Artes e Comunicação, Universidade Estadual Paulista "Júlio de Mesquita Filho", Bauru, SP, Brasil. Recuperado de https://alsafi.ead.unesp.br/handle/1 1449/121244

Souza, I. F., Teixeira, K. M. D., Loreto, M. D. S., \& Bartolomeu, T. A. (201 1). "... Não tem jeito de acordar hoje e dizer: hoje eu não vou ser mãe!": Trabalho, Maternidade e Redes de Apoio. Oikos. Revista de Economia Doméstica, 22(1), 46-63. Recuperado de http://www.seer.ufv.br/seer/oikos/index.php/ httpwwwseerufvbrseeroikos/article/view/21

Spindola, T., \& Santos, R. S. (2003). Trabalhando com a história de vida: percalços de uma pesquisa (dora?). Revista da Escola de Enfermagem da USP, 37(2), 1 19-1 26. Recuperado de http://www.scielo. $\mathrm{br} /$ scielo.php?script=sci_arttext\&pid=S0080$62342003000200014 \&$ lng $=$ pt\&tlng $=$ pt. doi: $10.1590 /$ S0080-62342003000200014

Stawinski, D., \& From, D. A. (2016). Liderança feminina nas organizações: desafios e oportunidades. Vitrine de produção acadêmica produção de alunos da faculdade dom bosco, 4(1), 166-176. Recuperado de http:// www.vitrineacademica.dombosco.sebsa.com.br/index. php/vitrine/article/view/155/156

Tamayo, A. (1998). Valores organizacionais: sua relação com satisfação no trabalho, cidadania organizacional e comprometimento afetivo. Revista de Administração, 33(3), 56-63. Recuperado de 200.232.30.99/ download.asp?file $=3303056$.pdf

Tamayo, A. (2000). Prioridades axiológicas e satisfação no trabalho. Revista de Administração, 35(2), 37-47. Recuperado de http://200.232.30.99/busca/artigo. asp?num_artigo $=63$

Teixeira, S. (2001). A gestão das organizações. Lisboa: McGraw-Hill.

Vergara, S. C. (2007). A liderança aprendida. GVExecutivo, 6(1), 61-65. Recuperado de http:// bibliotecadigital.fgv.br/ojs/index.php/gvexecutivo/ article/view/34329. doi: 10.12660/grexec. v6n 1.2007 .34329

Vicenzi, S. E., Bulgacov, S. (2013). Fatores motivadores do empreendedorismo e as decisões estratégicas de pequenas empresas. Revista de Ciências da Administração, 15(35), 208221. Recuperado de https://periodicos.ufsc. $\mathrm{br} /$ index.php/adm/article/view/23951. doi: $10.5007 / 2175-8077.2013 v 15 n 35 p 20$
Virtala, A., Kunttu, K., Huttunen, T., \& Virjo, I. (2006). Childbearing and the desire to have children among university students in Finland. Acta Obstetricia et Gynecologica Scandinavica, 85(3), 312-316. Recuperado de http://onlinelibrary.wiley.com/ doi/10.1080/00016340600555975/abstract. doi: $10.1080 / 00016340600555975$ 